UDK UDK 528.77

\title{
A COMPARISON ANALYSIS OF DIFFERENT PHOTOGRAMMETRIC SOFTCOPIES FOR GEODATA PRODUCTION
}

\author{
Mažena VOITECHOVIČ1, Birutė RUZGIENE் $\dot{2}^{2}$ \\ Vilnius Gediminas Technical University, Sauletekio al. 11, 10223 Vilnius, Lithuania \\ E-mails: ${ }^{1}$ mazena.viotechovic@stud.vgtu.lt; ${ }^{2}$ birute.ruzgiene@vgtu.lt (corresponding author) \\ Received 6 November 2014, accepted 28 November 2014
}

\begin{abstract}
Up-to-date mapping technologies for geodata production are widely applicable in Remote Sensing and Photogrammetry Communities. Therefore, the education in Remote Sensing and photogrammetric methods becomes very important using different image processing software for the terrain mapping purposes, spatial data modelling, etc. The use of new methods, technologies and professional widely-known systems demonstrates the desire to increase mapping capability. Despite that, digital didactics photogrammetric systems might be used (particularly in education process) simultaneously, this way getting more efficiency results. The objective of the research is to analyse some aspects of the use of digital photogrammetric softcopies, applied for terrain mapping: professional IMAGE ERDAS with LPS, LISA and Didactics Digital Photogrammetric Systems (DDPS). The experimental investigations lead to contiguity of this different software in consideration of the following criteria: accuracy, flexibility and time. The digital terrain models and orthophoto maps, created using two technologies, are almost the same due to time required for separate image processing steps. However, full workflow on DDPS requires about 2.5 times less time than on LPS. The photogrammetric measurement results demonstrate that there are some differences in accuracy due to stereoscopic measurements. When processing the images, the defined value of accuracy estimators meets the requirements for topographic mapping; however, DEM needs a separate study.
\end{abstract}

Keywords: photogrammetry, image processing, different software, orthophoto, accuracy evaluation.

\section{Introduction}

Modern digital image processing technologies have a potential to improve the photogrammetric production in terms of the cost and performance. Currently, the digital production of three dimensional (3D) surface models and orthophotos is becoming more popular. Such production is realised by Digital Photogrammetric Workstations (DPW) (Manual 2004; Kraus 2000; Ruzgienè 2008).

In digital photogrammetry, some photogrammetric operations are performed by monocular mode; however, the system of stereoscopic view is one of main parts of DPWs. Sophisticated computer hardware simplifies photogrammetric measurement processes; e.g., such flat monitor as SD2620W, WUXGA provides a high resolution $3 \mathrm{D}$ images and the stereoscopic image can be observed by multiple users. A variety of digital photogrammetric software is designed; however, systems differ in functionality, feature complexity and cost. The most common of the Digital Photogrammetric Workstations are: SOCET SET, BAE Systems (USA); Softplotter, Autometric (USA); ImageStation, Z/I Imaging (Germany/USA) (Z/I Imaging 2014); Cardinal Systems, Vrtwo (Cardinal systems 2014); Geomatica PSI (Canada); Delta, Geosystems (Ukraine); PHODIS, Zeiss (Germany); PHOTOMOD, Racurs, Moscow (Russia) and others. The short overview of some other photogrammetric systems (Digital 2014): AU4, Cartodata's is designed for large scale mapping purposes; using Summit Evolution, DATEM objects of $3 \mathrm{D}$ can be extracted from photographs, it is possible to directly introduce geodata to GIS systems, software processes various types of photographic images and data (aerial photographs, high resolution satellite and radar images), point cloud from Aerial Laser Scanning, automatically generates orthophotos; Leica Photogrammetry Suite (LPS) from ERDAS, Leica Geosystems Geospatial Imaging is well known 
software for Remote Sensing image processing (Butowtt, Kaczyński 2010).

In Lithuania, the photogrammetric workstation PHOTOMOD is used in some production and education institutions. The main features of this software are: an interactive stereoscopic model creation, aerial triangulation, a digital terrain model and ortho image generation, images mosaicking, integration of several projects, etc. (Racurs 2014).

While implementing digital photogrammetric technologies for the highest productivity, the comparison analysis of softcopies, applied in such processes as images orientation, aerial triangulation, digital terrain model and orthophotos generation, is relevant (Nurminen et al. 2013; Luhmann et al. 2006; Ruzgienè 2010). The investigations in such criteria as system flexibility, production time, accuracy and cost consideration should be significant. The decision on the mapping systems could lead to more flexible map production, reduced costs and time consumption considering project deadline requirements and increasing the demand for digital data and topographic maps from imagery, as well as their use in educational processes.

The objectives of the research is to analyse the main aspects of functionality in digital professional and didactics photogrammetric mapping software for the generation of $3 \mathrm{D}$ photogrammetric production in order to investigate the two systems through experiments and evaluate the accuracy of obtained geodata.

\section{Methodology}

The availability of different photogrammetric software has turned photogrammetric operations into a common procedure. The goals of digital photogrammetry are: to establish the relationship between image space and object space using photographs, to describe mathematical calculation of point coordinates based on camera calibration parameters, to measure images coordinates and ground control points (Wolf, Dewitt 2000). When stereo model is created, the relation between image and control points coordinates is established automatically and collection of $3 \mathrm{D}$ data is possible.

Digital photogrammetric systems have potential for processing image data from different sources (Kraus 2007; Ruzgiene, Žalnierukas 2011); scanned aerial photographs can be used as well. The professional photogrammetric scanners are very sensitive instruments; however some errors may appear due to proper calibration, environmental, maintenance conditions and image processing software. The high scan resolution as $14 \mu \mathrm{m}$ is required for better interpretability and higher accuracy.

The orthophotography production is an automated process because of that there is some cost variation in any country. The orthophotographic mapping when aerial photography is taken with analogue aerial camera is based on costs per image scanning - €10; aerial triangulation - €20; generation of digital elevation model - €90; orthophoto generation - $€ 25$ (Konecny 2003).

The usage of the different digital systems that complement each other is appropriate solution in getting complete knowledge for imagery processing and orthophoto generation as well. The education in photogrammetric images processing becomes increasingly important because of widely demand for applicability in Photogrammetry Communities. The training is based on usage of different software for processing of digital images. Digital image processing systems depends to set of high-level systems. Educational software is high desirable because of getting results in low time consuming and easy to use.

One of the main tasks in imagery processing is feature extraction, digitizing in spatial mode and getting vector data from stereo images. Only majority of educational systems has ability for stereo measurements. One of example in education process of that subject can be used Geo-Software LISA (Digital Photogrammetric Work Station) developed at University of Hanover (Germany). The advantage of usage the LISA is that it allows the control in orthorectification selecting several standard methods of interpolations as well as digital data filtering can be applied. This software's flexibility allows making decision on appropriate selection, to compare image processing time duration and accuracy of interpolation, to test chosen methods (Linder 2009).

For analysis in images processing is realized on the base of two aspects: use educational Digital Didactic Photogrammetric Station (DDPS) and professional photogrammetric software Leica Photogrammetry Suite (LPS) ERDAS IMAGINE.

The software DDPS was developed within the framework of a cooperative project between the Surfaces Laboratory, Department of Geomatics, University of Liege (supervising by Prof. J. P. Donnay), Belgium and the Institute of Geodesy and Cartography (IGiK), Department of Photogrammetry (supervising by Prof. R. Kaczynski), Poland. DDPS is 
complete and integrated photogrammetric package with user-friendly interface and easy for usage (Donnay, Kaczynski 2005). A complete photogrammetric images processing is possible with Digital Didactics Photogrammetric Software with realized workflow showed in Figure 1.

A very popular and professional software ERDAS IMAGINE suite of Leica Geosystems (Erdas Imagine 2014) is used for generation of the Earth surface model from imagery. It is the world's leading geographic imaging software for remote sensing and GIS needs. ERDAS IMAGINE offers a comprehensive solution that features extensive image processing capabilities: wide range of image classification tools, advanced and simple georeferencing, automated map production, transformation imagery into accurate GIS data, three-dimensional visualisation, etc. Leica Photogrammetry Suite (LPS) ERDAS is an image processing and workflow-driven system, which consists of numerous photogrammetric production tools. The following functions can be performed using the LPS: measurements of GCPs and tie points on multiple images, quality control; use of photography or satellite imagery from various types of sensors of cameras and satellites, triangulate multiple images automatically, orthorectify multiple images, etc. The general workflow on the LPS involves: coordinate system selection, definition of camera calibration parameters, choosing of image data, interior and exterior orientation, aerial triangulation, DEM creation and orthophoto generation (Fig. 2).

\section{Experiments and comparison analysis of different softcopies}

The experiments aimed to investigate the workflow on digital photogrammetric systems for production of professional and didactic geodata; to compare image processing results; to analyse and evaluate different softcopies in terms of their flexibility, time consumption and accuracy.

As input data, the analogical images at a scale of $1: 6000$ with $62 \%$ forward and $33 \%$ sideward overlap and covering the northern-eastern part of Vilnius were used for experimental measurements. The flight height was about $1000 \mathrm{~m}$, the images were taken by calibrated aerial camera $R M K$ TOP with the camera's focal length of $153.6 \mathrm{~mm}$. The diapositives were scanned with pixel size $14 \mu \mathrm{m}$ by photogrammetric scanner Vexell Ultra Scan. Digital photogrammetric images were of the size amounting to $16862 \times 16861$ pixels.

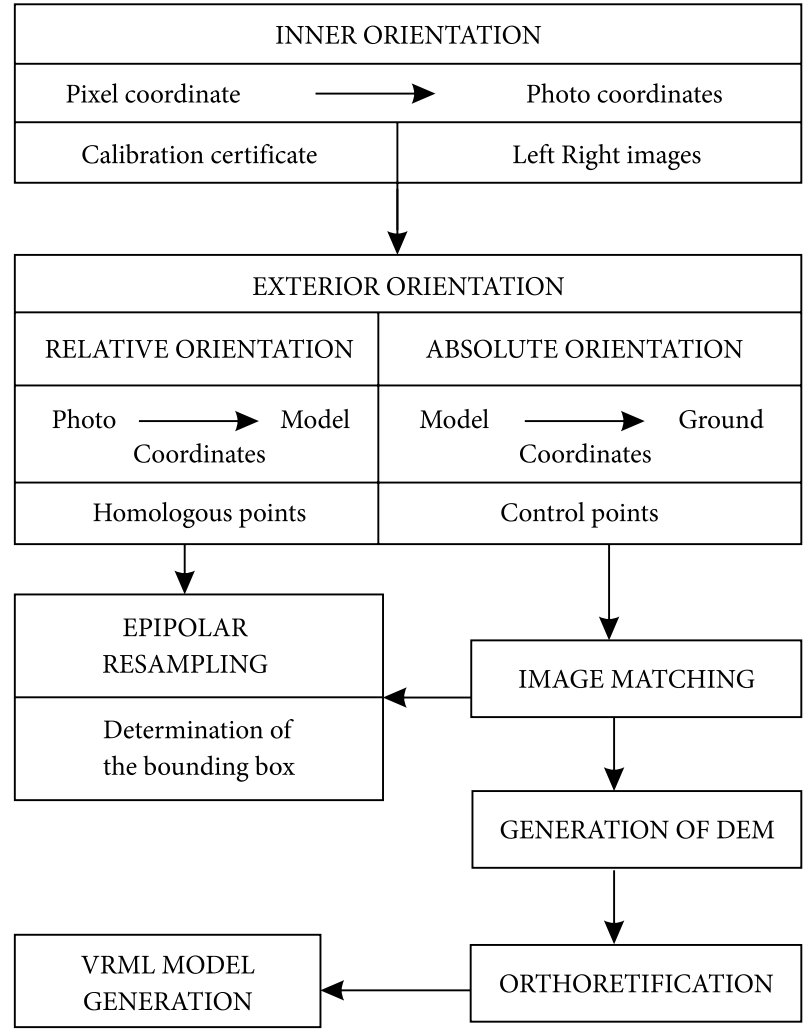

Fig. 1. General workflows on DDPS

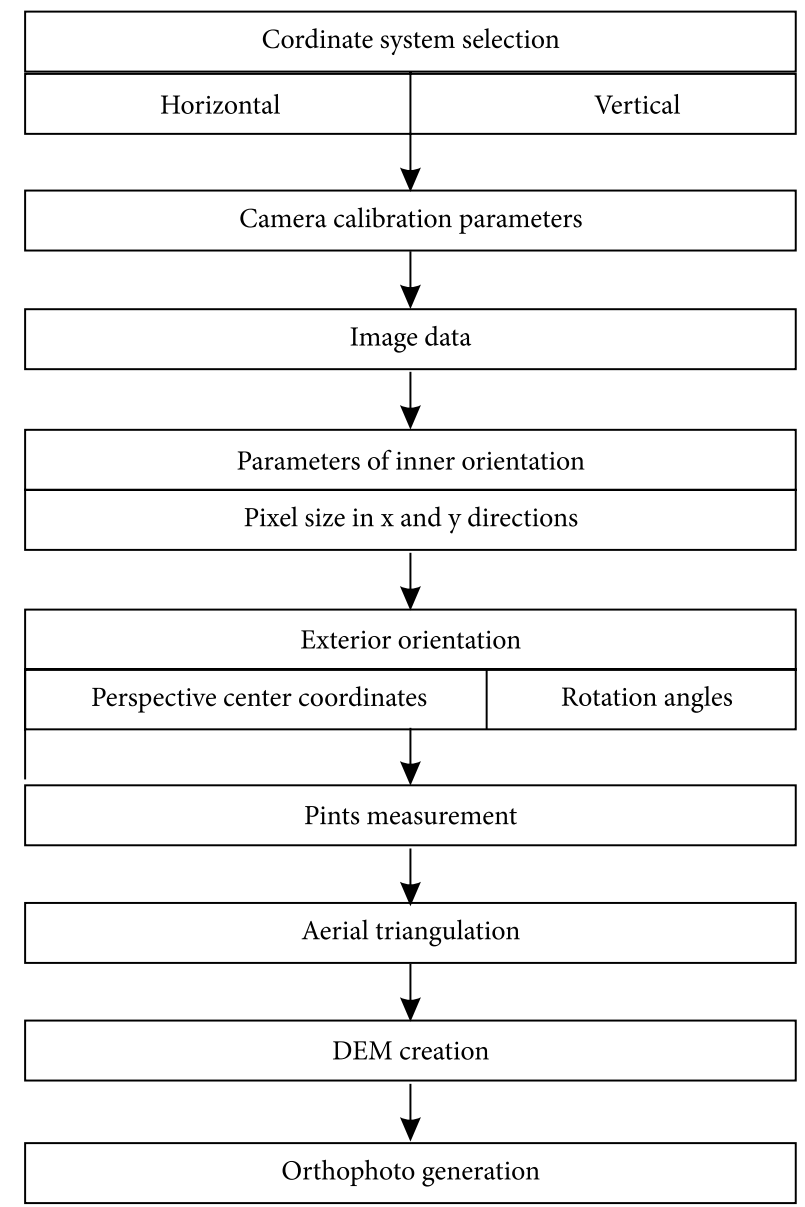

Fig. 2. General workflows on LPS 
The control point network was created using the photogrammetric technique of aerial triangulation and based on GPS measurements.

The accuracy of the image point position depends on characteristics of the camera sensor, the flight height, positioning of the GPS system, and some other factors.

The ground reference points were signalised on the territory before aerial photography and their coordinates were determined with the help of the GPS. Coordinates were transformed into the Lithuanian
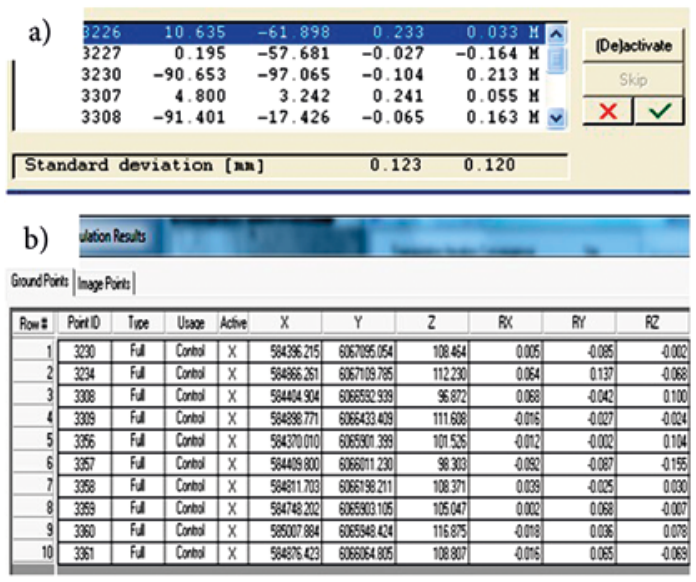

c)

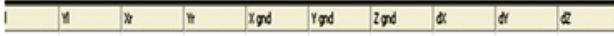

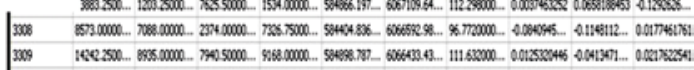

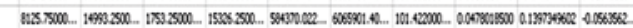

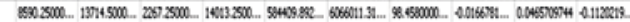

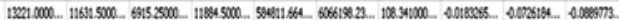
150 1.

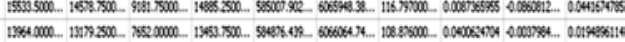

Fig. 3. Fragment of results from exterior orientation of left image on different software: a) LISA - the maximum residual error is $0.24 \mathrm{~m}$; b) LPS $-0.15 \mathrm{~m}$; c) DDPS - $0.14 \mathrm{~m}$

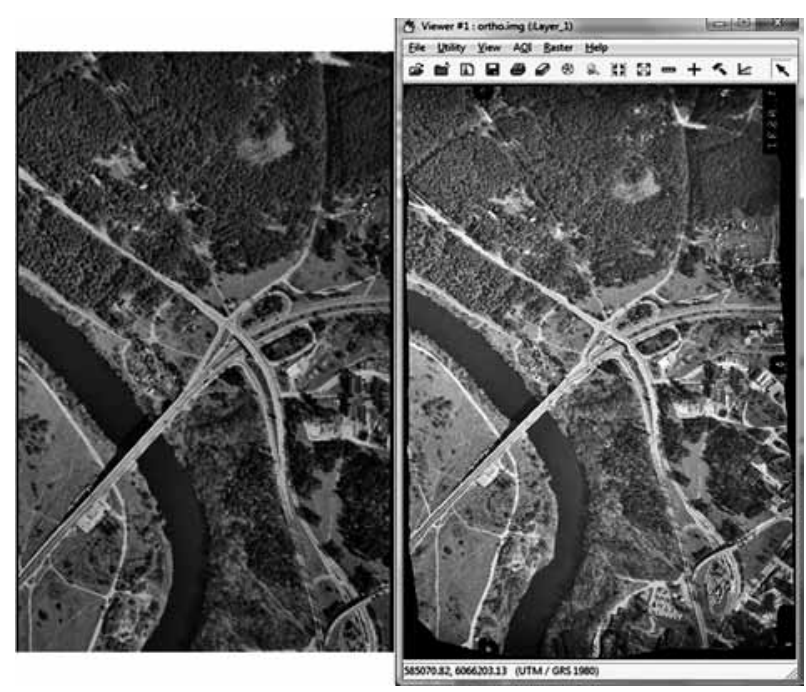

Fig. 4. Generated orthophotos in DDPS (left) and LPS (right) applications coordinate system LKS-94, while heights - into the Baltic height system. The accuracy was about $2-3 \mathrm{~cm}$.

During the flight, camera positioning by the kinematic GPS had a RMS $\pm 5-10 \mathrm{~cm}$ and IMU $- \pm 0.005-$ 0.01 gon, when flight height was of $1000 \mathrm{~m}$, such drift caused a shift of around $10-15 \mathrm{~cm}$ on the ground.

Applying the aerial triangulation method, the dense ground control point network was created. The model of mathematics block network adjustment has been based on collinearity equations. Equations of aircraft GPS antenna coordinate corrections are involved into the process of adjustment. The accuracy of photogrammetric block adjustment - the estimator of the variance $\left(\sigma_{0}\right)$ - reached up to $8.28 \mu \mathrm{m}$ in an image.

An aerial image at a scale of 1:6000 provides a positional restitution of about $20 \mathrm{~cm}$, and images scanned at $14 \mu \mathrm{m}$ are suitable for generation of $8 \mathrm{~cm}$ ground pixel orthophotos. Therefore, the input data for image processing should satisfy the requirements for the creation of reference geodata base at a scale of 1:1000-1:2000.

The image processing was performed on professional digital photogrammetric software Leica Photogrammetry Suite (LPS), ERDAS IMAGINE; LISA Geo-Software and Digital Didactic Photogrammetric Station (DDPS).

The accuracy results for the interior and relative orientation by DDPS, LISA and LPS, respectively, are: maximal residual for the plane affine transformation $-0.007 \mathrm{~mm} ; 0,012 \mathrm{~mm} ; 0.010 \mathrm{~mm}$.

Exterior (absolute) orientation of photographic images was based on 11 reference points, the rectangular coordinates of which were defined by the aerial triangulation approach. The results of the absolute orientation of an image using different software are shown in Figure 3.

The accuracy of image orientation obtained by different software (DDPS, LISA and LPS) is similar. The exterior orientation using DDPS and LPS softcopies was performed with the accuracy of up to $15 \mathrm{~cm}$.

The experimental area is not very roughed and not very densely populated with high buildings; therefore, image matching by DDPS and LPS software results show a rather low number of wrong point positions and the need for manual corrections is only about $5 \%$. Figure 4 shows the generated orthophoto using software DDPS and LPS.

The mapping processes by LPS ERDAS require a highly skilled employee, good knowledge in software operations, photogrammetry, image processing, etc. Both digital systems are flexible because of high 
automation of most procedures. The operator's work is easier on the DDPS system. Feature interpretation capabilities are not maximally effective, because the stereo viewing was impossible.

Time consideration. The inner orientation on the DDPS requires more time than on the LPS. The amount of labour time required for the creation of a digital terrain model depends of terrain types: flat or hilly, area covered by vegetation (for example, forests), urban or unbuilt territory. The DEM generation of complicated area in digital systems offers a large number of wrong measurements and needs extensive interactive corrections. In the test area, the terrain is rather open and not too roughed. Therefore, automatic DEM were processed successfully - only $2 \%$ of blunders were detected. The time required to receive cartographic products on the DDPS was about 2.5 times less than in case of the LPS.

Accuracy consideration. The goal was to investigate the point accuracy from processed image data by different software in the test area. For the evaluation of the geometric accuracy of image data, a comparison with results from stereoscopic measurements using LISA software was carried out. Applying the approach of stereo measurements, a number of image points (65 points) were coordinated. Figure 5 shows a fragment of points selected for investigation in the LPS application.

The search for image points for control was carried out at a variable distances, e.g. from 1.0 to $20 \mathrm{~m}$. The distribution of height deviations regarding the stereoscopic measurements is presented in Table 1.

The accuracy of the image height points was investigated comparing the results of image data processing with stereoscopic measurements. Root Mean Square (RMS) and Standard deviation $\operatorname{StD}\left(\sigma_{z}\right)$ were calculated using formulae (1), this way reducing the influence of systematic errors (Žalnierukas et al. 2009).

$$
\sigma_{z}=\sqrt{\frac{1}{n}\left(\sum \Delta^{2} Z-n \bar{\Delta}^{2} Z\right),} \quad(\mathrm{RMS})^{2}=\sigma_{z}^{2}+\bar{\Delta}^{2} Z,
$$

where $\Delta Z=Z_{\text {img }}-Z_{\text {stereo }}, \bar{\Delta} Z$ - mean of deviations, $n-$ number of checked points.

The differences of ground point coordinates defined by both digital photogrammetric systems were calculated and the accuracy estimators were determined. Table 2 presents the results of the investigation on the accuracy of point coordinates compared with stereoscopic measurements.

Results from the accuracy analysis show that the accuracy of geodata collected from two systems is approximately of the same level (planimetrical positional RMSE $-0.66 \mathrm{~m}$, heights $-0.86 \mathrm{~m}$ ). However,

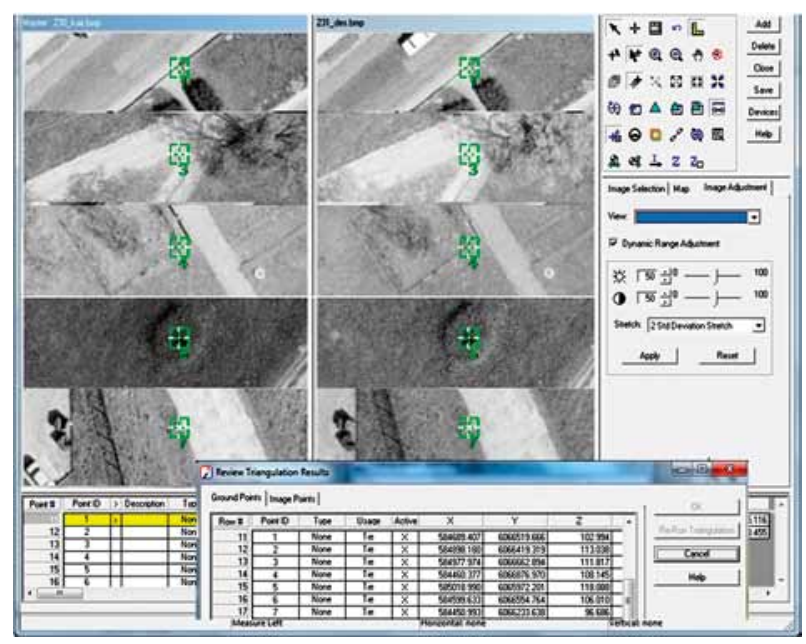

Fig. 5. Fragment of points selected for coordinates checking

Table 1. Distribution of point numbers regarding the defined height deviations

\begin{tabular}{|c|c|c|c|c|c|c|c|}
\hline \multirow{2}{*}{$\begin{array}{c}\text { Technology / } \\
\text { number of } \\
\text { points } \\
\text { (total 65) }\end{array}$} & \multicolumn{7}{|c|}{ Number of deviations at intervals, $\mathrm{m}$} \\
\cline { 2 - 8 } & 0 & $0.1-0.6$ & $0.6-1.1$ & $1.1-1.5$ \\
\cline { 2 - 8 } & + & - & + & - & + & - \\
\hline DDPS & - & 40 & 1 & 0 & 8 & 16 & 0 \\
\hline$L P S$ & - & 18 & 9 & 2 & 9 & 27 & 0 \\
\hline
\end{tabular}

Table 2. Results of the investigation on the accuracy of point coordinates compared with stereoscopic measurements

\begin{tabular}{|c|c|c|c|c|c|c|}
\hline \multirow{2}{*}{$\begin{array}{l}\text { Measurement } \\
\text { technologies }\end{array}$} & \multirow{2}{*}{$\begin{array}{l}\text { Checked } \\
\text { point } \\
\text { number }\end{array}$} & \multicolumn{5}{|c|}{ Accuracy assessments, $\mathrm{m}$} \\
\hline & & $\begin{array}{c}\text { Min. } \\
\text { deviation }\end{array}$ & $\begin{array}{c}\text { Max. } \\
\text { deviation }\end{array}$ & $\begin{array}{c}\text { Mean absolute } \\
\text { deviation }\end{array}$ & $\begin{array}{l}\text { Estimator, } \\
\text { RMS }\end{array}$ & Estimator, StD $(\sigma)$ \\
\hline \multicolumn{7}{|c|}{ Accuracy of planimetric coordinates $(x, y)$} \\
\hline DDPS & \multirow{2}{*}{65} & 0.28 & 0.85 & 0.59 & 0.66 & 0.29 \\
\hline LPS & & 0.27 & 0.92 & 0.63 & 0.65 & 0.18 \\
\hline \multicolumn{7}{|c|}{ Accuracy of point heights } \\
\hline DDPS & \multirow{2}{*}{65} & 0.30 & 1.40 & 0.26 & 0.79 & 0.63 \\
\hline$L P S$ & & 0.41 & 1.46 & 0.51 & 0.93 & 0.78 \\
\hline
\end{tabular}


point heights were determined with a lower accuracy, when collected on the LPS. Performing many trials, with accurate identification of selected image points, the accuracy investigation results remain the same as shown in Table 2. Therefore, these are significant values of accuracy estimators corresponding to especially accurate stereoscopic measurements.

\section{Conclusions}

Digital technologies without any doubt have a possibility to generate new accurate mapping products that require less time. However, user needs should be considered while choosing digital photogrammetric mapping technologies (production or educational).

The investigation has shown the functionality of two photogrammetric softcopies (DDPS and LPS ER$D A S)$ and their application possibilities. Feature extraction from images by manual mode on the DDPS is not very desirable, as it produces some inconveniences in management of images; in addition, there is no possibility to process images from a digital camera. Consequently, the algorithm used in the DDPS software should be supplemented. The digital photogrammetric image processing is fully reliable and functional with a lot of possibilities, when using a professional softcopy such as the LPS ERDAS.

The stereoscopic measurement approach was used as a more relevant technique due to investigations on the accuracy of photogrammetric measurements. Accuracy assessments with point coordinates determined using different softcopies shows that results match the accuracy requirements for a mapping product; however, more attention should be paid while generating an elevation model. The results of the accuracy investigation show conformity to the requirements for topographic mapping at scales of 1:5000-1:10000.

\section{References}

Butowtt, J.; Kaczyński, R. 2010. Fotogrametria. Warszawa: Wojskowa Akademia Techniczna. P. 280

Cardinal systems [cited 20 April 2014]. Available from Internet: www.pubs.usgs.gov

Digital photogrammetric workstations [cited 8 May 2014]. Available from Internet: http://www.gim- international. com/productsurvey/id36- Digital_Photogrammetric_ Workstations,December.html

Donnay, J. P.; Kaczynski, R. 2005. Didactic and digital photogrammetric software. Department of Geomatics, University of Liege, Belgium, Institute of Geodesy and Cartography (IGiK), Department of Photogrammetry, Warszawa, Poland. $71 \mathrm{p}$.

Erdas Imagine [cited 19 May 2014]. Available from the Internet: http://geospatial.intergraph.com/Homepage.aspx.
Konecny, G. 2003. Geoinformation: remote sensing, photogrammetry and geographical information systems. London and New York: Taylor and Francis. 248 p.

http://dx.doi.org/10.4324/9780203469644

Kraus, K. 2000. Photogrammetry, vol 1.: Fundamentals and standard processes. Köln: Dümmler. 397 p.

Kraus, K. 2007. Photogrammetry: geometry from images and laser scans. Berlin Walter de Gruyter. $459 \mathrm{p}$. http://dx.doi.org/10.1515/9783110892871

Linder, W. 2009. Digital photogrammetry. A practical course. Berlin Heidelberg: Springer-Verlag. 220 p. http://dx.doi.org/10.1007/978-3-540-92725-9

Luhmann, T.; Robson, S.; Kyle, S.; Harley, I. 2006. Close range photogrammetry. principles, methods and applications. Scotland, UK: Whittles Publishing. 510 p.

Manual of Photogrammetry. C. McGlone (Ed.). 2004. American Society for Photogrammetry and Remote Sensing, USA. 1151 p.

Nurminen. K.; Karjalainen, M.; Yu, X.; Hyyppä, J.; Honkavaara, E. 2013. Performance of dense digital surface models based on image matching in the estimation of plot-level forest variables, ISPRS Journal of Photogrammetry and Remote Sensing 83: 104-115.

Racurs [cited 6 May 2014]. Available from Internet: http://www. racurs.ru

Ruzgienè, B. 2008. Fotogrametrija. Vilnius: VGTU, Technika. 203 p. http://dx.doi.org/10.3846/987-S

Ruzgiene, B.; Xiang, G. Y.; Gečyte, S. 2011. Large scale city mapping using satellite imagery, Geodesy and Cartography 37(4): 168-171. http://dx.doi.org/10.3846/13921541.2011.645348

Ruzgienè, B. 2010. Skaitmeninio reljefo modelio kūrimo metodai ir tikslumo tyrimas, taikant skaitmeninès fotogrametrijos technologiją [Methods of digital relief model creation and accuracy investigation applying digital photogrammetry technology], Geodezija ir Kartografija [Geodesy and Cartography] 36(2): 57-62. http://dx.doi.org/10.3846/gc.2010.09

Ruzgiene, B.; Žalnierukas, A. 2011. Creation of an urban spatial model using laser-scanning, in The 8th International Conference "Environmental Engineering" 3: 1455-1458.

Wolf, P. R; Dewitt, B. A. 2000. Elements of Photogrammetry with Application in GIS. USA, McGraw-Hill. 608 p.

Z/I Imaging [cited 20 April 2014]. Available from Internet: http://www.ziimaging.com/en/products_15.htm

Žalnierukas, A.; Ruzgienè, B.; Kalantaitè, A.; Valaitienè, R. 2009. Miestų skenavimo LIDAR metodu tikslumo analizè. [Analysis of accuracy of Lithuanian city scanning applying the LIDAR method], Geodezija ir Kartografija [Geodesy and Cartography] 35(2): 55-60.

http://dx.doi.org/10.3846/1392-1541.2009.35.55-60

Mažena VOITECHOVIČ. Master's degree student. Vilnius Gediminas Technical University, Faculty of Environmental Engineering, Saulètekio al. 11, LT-10223 Vilnius, Lithuania (phone: +3705 2744703).

Research interests: GIS, 3D photogrammetric modelling.

Birutė RUZGIENĖ. Associate Professor, Doctor. Vilnius Gediminas Technical University, Dept. of Geodesy and Cadastre, Saulètekio al. 11, 10223 Vilnius, Lithuania (phone: +370 5 2744703).

Research interests: digital photogrammetric mapping, image interpretation, features extraction from remote sensing data. 